\title{
Emotional eating, snacking behavior and nutritional status among adolescents
}

\author{
Yulia Rachmawati ${ }^{1}$, Sapja Anantanyu², Kusnandar ${ }^{3}$ \\ ${ }^{1}$ Department of Nutrition, Postgraduated Program, Universitas Sebelas Maret, Indonesia \\ ${ }^{2,3}$ Faculty of Agriculture, Universitas Sebelas Maret, Indonesia
}

\section{Article Info \\ Article history: \\ Received Sep 29, 2019 \\ Revised Oct 10, 2019 \\ Keywords: \\ Adolescent \\ Emotional eating \\ Nutritional status \\ Overweight \\ Snacking behavior}

Accepted Nov 15, 2019

\begin{abstract}
The tendency to eat in response to stress known as emotional eating (EmE). Individuals with EmE usually has been change their dietary pattern towards more unhealthy snacking which contribute to overweight. This study aims to examine the interrelationship between EmE, snacking behavior and nutritional status among adolescents. This was an analytic observational with a cross sectional design study. It was conducted in Surakarta, on August 2019. Total 140 adolescents aged 14-17 years were selected. The data of EmE were measured by Emotional Eater Questionnaire (EEQ), data of snacking behaviour measured by food frequencies questionnaire (FFQ), and BMI were measured using weight scale and microtoice. Data were analyzed by descriptive, bivariate and binary logistic using SPSS v.23. There was significantly difference of $\mathrm{EmE}$ and snacking behavior in underweight, normal, and overweight adolescents. We found that underweight $(4.17 \pm 3.16)$ and normal individuals $(4.97 \pm 4.19)$ were not an emotional eater, and less sweet snacks and sweet drinks consumption while overweight individuals were an emotional eater (14.26 \pm 6.04$)$ and eat more sweet snacks, and sweet drinks $(\mathrm{p}<0.001)$ during negative emotional states. It was shown that emotional eating and snacking behavior were found higher in overweight than underweight and normal individuals.
\end{abstract}

Copyright (c) 2019 Institute of Advanced Engineering and Science. All rights reserved.

\section{Corresponding Author:}

Yulia Rachmawati

Department of Nutrition, Postgraduated Universitas Sebelas Maret,

Jl. Ir Sutami No.36 A, Pucangsawit, Kec. Jebres, Kota Surakarta, Jawa Tengah 57126.

Email: yulia.rachmawati66@gmail.com

\section{INTRODUCTION}

Adolescence is a transitions period between childhood and adulthood. Pubertal transition is characterized by physically growth, cognitive and psychosocial development. An adolescent will experience a 'period of storm and stress' which emotional tension occurs as the result of physical, psychosocial, and hormonal changes. This situation makes adolescents tend to get more psychological stress and cause negative emotions such as anxiety, depression, and stress [1]. In the state of emotional tension in response to a difficult experience also results in physiological and behavioral changes, including eating behavior [2]. The tendency to eat in response to the negative emotions is well known as emotional eating (EmE) [3]. Some individuals use Emotional Eating (EmE) as a method of escaping emotional distress. Adolescents with emotional eating disorder tend to feel excessive hunger and increasing the frequency of snacking sweet high energy-dense foods such as cake, ice cream, chocolate and soda. Several studies have shown that increased frequencies of snacking habits implicated in increased body weight and risk for overweight and obesity in the various age group [4-6]. Moreover, using food in response to stress has been identified as a mediator between stressful life experience and indicator of obesity [7].

According to WHO, approximately 18\% children and adolescents aged 5-19 years are considered overweight and obese. Children and adolescent with overweight and obesity are higher risk for developing 
the same problem in adulthood and cause many chronic diseases, including coronary heart disease, type 2 diabetes, and certain cancers [8-9]. In Indonesia, overweight and obesity is still high prevalent. In 2013, prevalence of overweight among adolescents aged 16-18 still 7.3\% (5.7\% overweight; 1.6\% obesity). Central Java is one of the highest prevalence of obesity case with $1.8 \%$, and Surakarta City is the highest prevalence of overweight and obesity case with $6.4 \%$ and $5.9 \%$ [10].

\section{RESEARCH METHOD}

This was an analytic observational with a cross sectional design study. It was conducted in four high school in Surakarta, on August 2019. Total population in this study was 2754 adolescents, and sample size was counted by Open Epi application. Total 140 adolescents aged 14-17 years was sampling by cluster random sampling technique. Subject who consumed anti-depressants, anti-anxiety, mood stabilizers, anti-psychotic medication, appetite stimulant, and drugs stimulate weight gain were not included. Also, subject who was on menstrual period, or fasting were exclude from the study.

Dependent variable on this study was nutritional status, and independent variable was emotional eating and snacking behavior. Definition of nutritional status in this study was nutritional status of adolescents which measured by counted weight $(\mathrm{kg})$ per height $\left(\mathrm{m}^{2}\right)(\mathrm{BMI})$ per age. Definition of emotional eating in this study was the tendency to eat in response to the negative emotions during a month ago which measured by Emotional Eater Questionnaire (EEQ). EEQ consisted of 10 question about emotional eating with Likert Score 0 for never, 1 for sometimes, 2 for usually, and 3 for always. The results of EEQ would be classified into 4 which 0-5 was "non emotional eater"; 6-10 was "Low emotional eater"; 11-20 was "Emotional eater"; and 20-30 was "Very Emotional Eater". Snacking behavior is frequency of salty-sweet high fat and energy-dense snacks consumption during a month ago which measured by Food Frequency Questionnaire (FFQ). FFQ will consisted of high density snack or drink with Likert score 0 for never, 1 for 2-3 times a month, 2 for 2-3 times a week, 3 for daily, 4 for a couple times a day.

Statistical analyses were performed with SPSS V.23 (SPSS Inc., Chicago, IL, USA). Normality of data distribution was examined by Kolmogorov-Smirnov and non parametrics test were used because the data were abnormal. Bivariate test between each variable was examined by Kruskall-Wallis and Mann-Whitney U test. Mutivariate test was examined by Binary Regression. Value of $\mathrm{P}<0.005$ was considered as significant. Anonymity, confidentiality, and written informed consent were obtained from all subjects. The trial was approved by the Ethics Committee of Medicine Faculty of Sebelas Maret University, Surakarta No.314/UN27.06/KEPK/2019.

\section{RESULTS AND DISCUSSION}

\subsection{Characteristic of subjects}

At the beginning of the study, 144 subjects participated in this study, but four subjects did not complete the questionnaire and excluded. Therefore, the statistical analysis was performed on 140 subjects who completed the study. Characteristics of the study population including age, grade, pocket money, parent's education, parent's occupation, and family income were presented in Table 1. The majority of subjects $(58.6 \%)$ were $11^{\text {th }}$ grade student in high school, and the rest were $10^{\text {th }}$ grade. Based on the average pocket money, $77.9 \%$ of subjects had an average pocket money which was 20.807 .00 IDR per day. The majorities of subject's parent were bachelor, and worked as private employees, or entrepreneurs, while the majority of subject's mothers were housewives. The majority of subject' parents had an income above the Surakarta City Regional Minimum Wage in 2019 which was 1.802.700.00 IDR per month.

Table 1. Characteristic of subjects

\begin{tabular}{lcc}
\hline \multicolumn{1}{c}{ Category } & $\mathrm{F}$ & $\%$ \\
\hline Age (years) & 5 & 3.6 \\
14 & 57 & 40.7 \\
15 & 68 & 48.6 \\
16 & 10 & 7.1 \\
17 & & \\
Grade & 58 & 41.4 \\
$10\left(1^{\text {st }}\right.$ grade) & 82 & 58.6 \\
$11\left(2^{\text {nd }}\right.$ grade) & & \\
Pocket Money* & 109 & 77.9 \\
Under Average & 31 & 22.1 \\
Above Average & & \\
Father Education & &
\end{tabular}

Int. J. Public Health Sci. Vol. 8, No. 4, December 2019: 413-418 


\begin{tabular}{|c|c|c|}
\hline Elementary & 5 & 3.6 \\
\hline Junior High & 12 & 8.6 \\
\hline Senior High & 57 & 40.7 \\
\hline University & 66 & 47.1 \\
\hline \multicolumn{3}{|l|}{ Father Occupation } \\
\hline Civil servants & 34 & 24.3 \\
\hline State-Own Enterprises & 7 & 5.0 \\
\hline Enterpreneur/private employee & 81 & 57.9 \\
\hline Farmer/Laborer & 15 & 10.7 \\
\hline Retired & 3 & 2.1 \\
\hline \multicolumn{3}{|l|}{ Father Income $* *$} \\
\hline$<$ Regional Minimum Wage & 18 & 8.6 \\
\hline$\geq$ Regional Minimum Wage & 122 & 91.4 \\
\hline \multicolumn{3}{|l|}{ Mother Education } \\
\hline Elementary & 6 & 4.3 \\
\hline Junior High & 10 & 7.1 \\
\hline Senior High & 59 & 42.1 \\
\hline University & 65 & 46.4 \\
\hline \multicolumn{3}{|l|}{ Mother Occupation } \\
\hline Civil servants & 29 & 20.7 \\
\hline State-Own Enterprises & 2 & 1.4 \\
\hline Enterpreneur/private employee & 39 & 27.9 \\
\hline Farmer/Laborer & 1 & 0.7 \\
\hline Housewives & 69 & 49.3 \\
\hline \multicolumn{3}{|l|}{ Mother Income** } \\
\hline No income & 69 & 49.3 \\
\hline$<$ Regional Minimum Wage & 20 & 14.3 \\
\hline$\geq$ Regional Minimum Wage & 51 & 36.4 \\
\hline
\end{tabular}

\subsection{Bivariate analysis}

Nutritional status distribution based on gender is presented in Table 2. It can be seen that the majority of subjects (53.6\%) are female. The prevalence of underweight adolescents in this study was $8.5 \%$, with a higher prevalence of underweight among boys (5.0\%) than girls (3.6\%). Most $(67.1 \%)$ of subjects were normal with the prevalence of normal among girls (40.0\%) were higher than boys $(27.1 \%)$. The prevalence of overweight in this study is relatively high at $24.3 \%$ with the prevalence of overweight among boys (14.3\%) higher than girls (10.0\%).

Table 2. Characteristics of subject based on nutritional status and gender

\begin{tabular}{cccccccc}
\hline & \multicolumn{2}{c}{ Boys } & \multicolumn{2}{c}{ Girls } & \multicolumn{2}{c}{ Total } & \multirow{2}{*}{$P^{*}$} \\
& $\mathrm{n}$ & $\%$ & $\mathrm{n}$ & $\%$ & $\mathrm{n}$ & $\%$ & \\
\hline Underweight & 7 & 5.0 & 5 & 3.6 & 12 & 8.5 & \\
Normal & 38 & 27.1 & 56 & 40.0 & 94 & 67.1 & \multirow{2}{*}{0.126} \\
Overweight & 20 & 14.3 & 14 & 10.0 & 34 & 24.3 & \\
Total & 65 & 46.4 & 75 & 53.6 & 140 & 100 & \\
\hline
\end{tabular}

*Chi-square test with significant $\mathrm{p}<0.05$

These present study showed that the prevalence of adolescents with normal nutritional status was $67.1 \%$, underweight was only around $8.5 \%$; while overweight was relatively high at $24.3 \%$. This result is consistent with the situation in Indonesia which still experiencing double burden problems [11]. The present results support the prior research who found a higher prevalence of underweight among male adolescents than female adolescents [12]. However, from the chi-square test the difference of nutritional status based on gender was not statistically significant. This was also consistent with the prior research who found that gender differences were not related to nutritional status [13]. But another study found that overweight was closely correlated with gender [14].

The difference of emotional eating and snacking behavior based on the nutritional status of subjects were presented in Table 3. It can be seen that the average of emotional eating score of subjects with

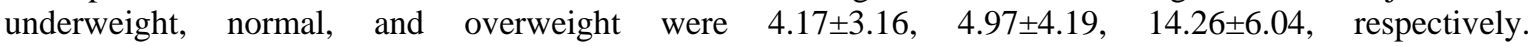
From the Kruskal Wallis test, obtained $\mathrm{p}$ value $<0.001$ which means there were differences in emotional eating scores based on the nutritional status of subjects. In Table 3 also could be seen the frequencies of snack consumption with indicators of sweet snacks, salty snacks, one meal dish and sweet drinks. The score of sweet snack consumption in underweight, normal, and overweight subjects were 1.39 \pm 0.57 , $2.41 \pm 0.79,5.08 \pm 1.81$ respectively, with $\mathrm{p}$ value $<0.001$. The score of salty snacks consumption in

Emotional eating, snacking behavior and nutritional status among adolescents (Yulia Rachmawati) 
underweight, normal and overweight subjects were $2.06 \pm 0.57,3.34 \pm 1.19,5.40 \pm 2.19$, respectively, with a $\mathrm{p}$ value $<0.001$. The score of one dish meal consumption in underweight, normal and overweight subjects were $1.81 \pm 0.73,2.60 \pm 1.22,3.86 \pm 1.47$ respectively, with $\mathrm{p}$ value $<0.001$. The score of sweet snack consumption in underweight, normal, and overweight subjects were $1.93 \pm 0.94,2.86 \pm 1.50,4.74 \pm 2.26$ respectively, with $\mathrm{p}$ value $<0.001$. Therefore, there were significant differences in the snacking behavior (sweet snack, salty snack, one dish meal, sweet drink) among underweight, normal and overweight subjects.

Table 3. Difference of emotional eating and snacking behavior based on nutritional status

\begin{tabular}{lccccccc}
\hline & \multicolumn{2}{c}{ Underweight } & \multicolumn{2}{c}{ Normal } & \multicolumn{2}{c}{ Overweight } & $p^{*}$ \\
& Mean & SD & Mean & SD & Mean & SD & \\
\hline Emotional Eating & & & & & & & \\
$\quad$ Non-EE & 2.38 & 1.68 & 2.62 & 1.99 & 2.50 & 3.53 & \\
LEE & 7.75 & 2.06 & 8.14 & 1.41 & 7.86 & 1.21 & \\
EE & - & - & 14.00 & 1.41 & 14.71 & 2.93 & $<0.001^{*}$ \\
$\quad$ VEE & - & - & 21.50 & 0.71 & 21.86 & 1.36 & \\
$\quad$ Rerata & 4.17 & 3.16 & 4.97 & 4.19 & 14.26 & 6.04 & \\
Snacking Behaviour & & & & & & & \\
$\quad$ Sweet Snacks & 1.39 & 0.57 & 2.41 & 0.79 & 5.08 & 1.81 & $<0.001^{*}$ \\
$\quad$ Salty Snacks & 2.06 & 0.57 & 3.34 & 1.19 & 5.40 & 2.19 & $<0.001^{*}$ \\
One dish meal & 1.81 & 0.73 & 2.60 & 1.22 & 3.86 & 1.47 & $<0.001^{*}$ \\
$\quad$ Sweet Drink & 1.93 & 0.94 & 2.86 & 1.50 & 4.74 & 2.26 & $<0.001^{*}$ \\
\hline
\end{tabular}

Note: Non-EE: Non-Emotional Eater; LEE: Low Emotional Eater; EE: Emotional Eater; VEE: Very Emotional Eater Eater; *Uji

Kruskal Wallis test signifikan $\mathrm{p}<0.05$

From the present results, emotional eating occurred among $49.3 \%$ of subjects both boys and girls. However, the prevalence of emotional eating among girls was slightly higher than boys. It was consistent with the previous research which found that emotional eating were higher prevalent in girls than boy. This was because women tend to experienced negative emotions such as stress (perceived stress), worry (worries), and anxiety (anxiety) psychologically, while men tend to experienced negative emotions only confusion (confused mood) feeling [15]. But, from the results of the average emotional eating score by gender, it was found that the average emotional eating score among boys was higher than girls, although not significantly different. This could be caused by the prevalence of overweight boys was higher than girls. This was supported by prior research which found that emotional eating were higher prevalent among overweight than underweight individuals [16].

Emotional eating was usually caused by several factors such as alexithymia, emotional regulation, and genetic disorders. Genetic factors were related to the Hypothalamic Pituitary Adrenal (HPA) response to stress by cortisol secretion, through a system called the serotonergic brain system. In the serotonergic brain system, the serotonin transporter gene (5-HTT-SLC6A4) had to regulate serotonin secretion which will stabilize appetite and body weight. If there was a disruption in the serotonergic brain system such as the occurrence of polymorphisms in the 5-HTTLPR allele gene, it will cause a decrease in serotonin secretion and cause feelings of depression and cause emotional eating disorders [17].

The present results showed a relationship between snacking frequencies with nutritional status using BMI per age indicators. We found that higher frequencies of snacking would positively affects the BMI score. This results supported by a cohort study which found that people who highly frequent of snacking experienced significant weight gain during the follow-up study. Individuals with highly frequent snacking behavior had $69 \%$ higher risk of overweight and obesity [18]. From the present results was also found that underweight to normal adolescents preferred to consume the type of salty snacks. Overweight adolescents preferred the type of sweet snacks and sugary drinks. Food preferences based on nutritional status theory was reported that individuals with overweight and obese tend to like snacks with sweet taste (bread, cakes, biscuits, chocolate), or sweet and milky drinks (tea, coffee, chocolate). Underweight individuals tend to choose boiled snacks, fruit and dairy products.

\subsection{Multivariate analysis}

Multivariate analysis between emotional eating, snacking behavior and nutritional status were presented in Table 4. It was known that the emotional eating variable had $\mathrm{p}$ value $=0.008$ and sweet snack variables had $\mathrm{p}$ value $<0.001$, so it was statistically significant. In other words, emotional eating variables and sweet snack consumption simultaneously affect the nutritional status of subjects. While other variables such as the salty snacks $(\mathrm{p}=0.080)$, one meal dish $(\mathrm{p}=0.191)$, and sweet drinks $(\mathrm{p}=0.149)$ consumption were not statistically significant $(>0.05)$ so these variables were not simultaneously affect the nutritional status of 
subjects. From the results above we obtained the regression equation $\mathrm{Y}=17.131+0.183 \mathrm{X} 1+2.213 \mathrm{X} 2-0.493$ $\mathrm{X} 3-0.381 \mathrm{X} 4-0.304 \mathrm{X} 5$ and resulted as $\mathrm{R}^{2} 68.9 \%$.

Tabel 4. Regression of emotional eating, snack behavior and nutritional status

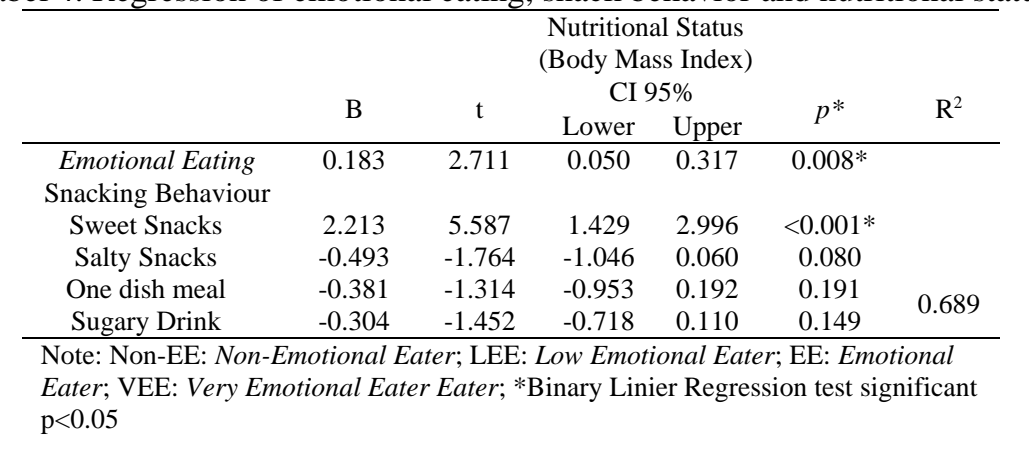

In this study, it was known that there was a relationship between emotional eating, snacking behavior, and nutritional status. Emotional eating disorders can changes the snacking behavior and contribute to changed nutritional status. In another words, individual with emotional eating or known as emotional eater tend to consumed higher frequent of snacking which cause higher body mass index which contributes to overweight. This result supported by previous study which found that overweight individuals tend to overeating during emotional states compared to underweight or normal individuals [18]. Previous research also found that adolescents who experienced emotional eating tend to consume sweet high energy-dense foods [15]. This was also found that emotional eating was positively related to higher consumption of high energy-dense, sweet, and high fat snack [20].

Children or adolescents who were experienced emotional eating tend to had restrained eater habits before. Individuals who usually restrained eating were usually able to control their eating strategies when the emotional state is neutral or positive, but when experienced stress or another negative emotions, it became uncontrollable so it affected the eating behavior [21]. The interrelationship between emotional eating, snacking behavior and nutritional status also supported by prior study which found that food was a comforting agent that provides comfort after consumed [22]. Physiologically, snack, especially sweet snacks, contained tryptophan which can help increased the serotonin hormone which raise sense of happiness, calm, and reducing the negative emotions [23]. Consequently, increased of calorie intake and imbalance sugar, high fat, low fiber diet contributes to higher BMI and risk of overweight and obesity [24]. Somehow, it could be also become a reciprocal relationship which individual with overweight and obesity could be very emotional eating and influenced the frequencies of snacking that cause the overweight or obesity could get worse [25].

\section{CONCLUSION}

Increased frequency of high density snack consumption due to emotional eating correlated with an increased of body mass index and contributes to overweight. And it was shown that emotional eating disorder and sweet-high density snacking behavior were found higher in overweight than underweight and normal individuals.

\section{ACKNOWLEDGEMENTS}

We are thankful to the subject who kindly participated in this trial. We also declared there is none conflict of interest.

\section{REFERENCES}

[1] Michels, N., et al., "Stress, Emotional Eating Behavior and Dietary Pattern in Children". Appetite, 59: 762-769. 2012.

[2] Wardle, J., et al., "Stress and adiposity: A meta-analysis of longitudinal studies". Obesity, 19, 771-778. 2011.

[3] Arnow, B., et al., "The Emotional Eating Scale: The Development of a Measure to Assess Coping with Negative Affect by Eating”. Stanford University Scool of Medicine. Vol. 18 (1). 1995.

[4] Barnes, T.L., et al., "Snacking Behaviors, Diet Quality, and BMI in a Community Sample of Working Adults". J Acad Nutr Diet 115(7): 1117-1123. 2015. 
[5] Gunes, F.E., et al.,"Relation between eating habits and a high body mass index among freshman students: a crosssectional study". J Am Coll Nutr 31(3):167-74. 2012.

[6] Smetanina, N., et al., "Prevalence of overweight/obesity in relation to dietary habits and lifestyle among 7-17 years old children and adolescents in Lithuania". BMC Public Health 15, 1001:1010. 2015.

[7] Greenfield, E.A., Marks, N. F., "Violence from parents in childhood and obesity in adulthood: Using food in response to stress as a mediator of risk". Social Science \& Medicine, 68, 791-798. 2009.

[8] Esser, N., et al.,"Inflammation as a link between obesity, metabolic syndrome and type 2 diabetes". Diabetes Research and Clinical Practice, 105, 141-150. 2014.

[9] Lavie, C.J., et al., "Obesity and cardiovascular disease: Risk factor, paradox, and impact of weight loss". Journal of the American College of Cardiology, 53, 1925-1932. 2009.

[10] Santoso, B., et al., "Basic Health Research of Central Java Province years of 2013". Litbangkes: Jakarta. 2013.

[11] Hanandita, W., Tampubolon, G., "The double burden of malnutrition in Indonesia: Social determinants and geographical variations". SSM -PopulationHealth: 16-25. 2009.

[12] Araújo, C, L., et al., "Nutritional status of adolescents: the 11-year follow-up of the 1993 Pelotas (Brazil) birth cohort study". Cad Saude Publica 26(10): 1895-1903. 2010.

[13] Salvador, C.C.Z., et al., "Nutritional status of children and adolescents: factors associated to overweight and fat accumulation". Journal of Human Growth and Development 24(3): 313-319. 2010.

[14] Mittendorfer, B., et al., "Relationship between body fat mass and free fatty acid kinetics in men and women". Obesity (Silver Spring). 17:1872-7. 2009.

[15] Nguyen-Michel, S.T., et al., "Dietary Correlates of emotional eating in adolescence". Appetite, 49 (2): 494-499. 2007.

[16] Van Strien, T., et al., "Emotional eating as a mediator between depression and weight gain." Appetite. 100:216-24. 2016.

[17] Van Strien, T., et al., "Emotional eating in adolescents: a gene (SLC6A4/5-HTT) e depressive feeling interaction analysis." Journal of Psychiatric Research, 44: 1035-1042. 2016.

[18] Bes-Rastrolo, M., et al., "Prospective study of self-reported usual snacking and weight gain in a Mediterranean cohort". Clinical Nutrition, 29(3): 323-330. 2010.

[19] Gelieber, A., Aversa, A., "Emotional eating in overweight, normal weight, and underweight individuals". Eating Behaviors, 3: 341-347. 2003.

[20] Konttinen, H., et al., "Emotional Eating, Deppresive Symptopms and Self-Reported Food Consumption: A Population-Based Study". Appetite, 54:473-479. 2010.

[21] Gibson, E.L., "Emotional influences on food choice: sensory, physiological and psychological pathways". Physiology and Behavior 89: 53-61. 2006.

[22] Dallman, M.F., et al., "Chronic stress and comfort foods: Self-medication and abdominal obesity". Brain, Behavior, and Immunity, 19: 275-280. 2005.

[23] Tan,C.C., Holub, S.C., "The Effects Of Happiness And Sadness On Children's Snack Consumption.” Appetite, 123:169-174. 2018

[24] Chambers,J.A., Swanson , V.,"A health assessment tool for multiple risk factors for obesity: results from a pilot study with UK adults". Patient Education and counseling, 62: 79-88. 2006.

[25] Schneider, K.L., et al., "Trait anxiety, but nor trait anger, predisposes obese individuals to emotional eating". Appetite, 55: 701-706. 2010. 